OPEN ACCESS

Edited by: Inna N. Lavrik

University Hospital

Magdeburg, Germany

Reviewed by:

Jiaxing Zhang,

Sun Yat-sen University, China

Mario Cioce,

Campus Bio-Medico University, Italy

${ }^{*}$ Correspondence:

Wen-Hui Chen

wenhuichen221@126.com Jian-Fu Zhao

594357558@qq.com

${ }^{\dagger}$ These authors have contributed equally to this work

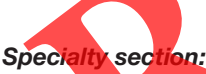

This article was sub

Cell Death and Survival,

a section of the journal

Frontiers in Cell and Developmental

Biology

Received: 25 September 2020

Accepted: 30 November 2020

Published: 05 February 2021

Citation:

Wu L-M, Liao X-Z, Zhang Y, He Z-R

Nie S-Q, Ke B, Shi L, Zhao J-F and

Chen W-H (2021) Parthenolide

Augments the Chemosensitivity of

Non-small-Cell Lung Cancer to

Cisplatin via the PIJKJAKT Signaling

Pathway.

Front. Cell Dev. Biol. 8:610097.

doi: 10.3389/fcell.2020.610097

\section{Parthenolide Augments the Chemosensitivity of Non-small-Cell Lung Cancer to Cisplatin via the PI3K/AKT Signaling Pathway}

\author{
Li-Mei Wu ${ }^{1+}$, Xiao-Zhong Liao ${ }^{2 t}$, Yan Zhang ${ }^{1+}$, Zi-Rui He ${ }^{1}$, Shi-Qing Nie ${ }^{1}$, Bin $\mathrm{Ke}^{3}$, Lin Shi ${ }^{4}$, \\ Jian-Fu Zhao ${ }^{1 *}$ and Wen-Hui Chen ${ }^{1 *}$ \\ 'Department of Oncology, The First Affiliated Hospital of Jinan University, Guangzhou, China, 'Department of Oncology, The \\ First Affiliated Hospital of Guangzhou University of Chinese Medicine, Guangzhour, China, ${ }^{3}$ Department of Jraditional Chinese \\ Medicine, Cancer Center of Sun Yat-sen University, Guangzhou, China, ${ }^{4}$ Department of Traditional Chinese Medicine, \\ Zhujiang Hospital, Southern Medical University, Guangzhou, China
}

The mortality rate of non-small-cell lung cancer (NSCLC) remains high worldwide. Although cisplatin-based chemotherapy may greatly enhance patient prognosis, chemotherapy resistance remains an obstacle to curing patients with NSCLC. Therefore, overcoming drug resistance is the main route to successful treatment, and combinatorial strategies may have considerable clinical value in this effort. In this study, we observed that both parthenolide (PTL) and cisplatin (DDP) inhibited the growth of NSCLC cells in a dose- and time-dependent manner. The combination of PTL and DDP presented a synergistic inhibitory effect on NSCLC at a ratio of 50:1. The combination of PTL and DDP synergistically inhibited cell migration and invasion, inhibited cell cycle progression, and induced apoptosis of A549 and PC9 cells. Bioinformatics and network pharmacology analysis indicated that PTL may primarily affect the phosphatidylinositol 3-kinase (PI3K)-AKT signaling pathway. After treatment with PTL and DDP either alone or n combination, Western blot analysis revealed that the proteins levels of Bax and cleaved Caspase-3 were upregulated, while p-PI3K, p-Akt, Caspase-3, and Bcl-2 proteins were downregulated. Among these alterations, the combination of PTL and DDP was found to exhibit the most significant effects. PTL might therefore be considered as a new option for combination therapy of NSCLC.

Keywords: PTL, DDP, combination, synergistic effect, NSCLC, PI3K/Akt pathway

\section{INTRODUCTION}

Lung cancer is the most common and most aggressive malignancy, as well as the principal cause of cancer-related deaths in both men and women all over the world (Siegel et al., 2018) and in China (Chen et al., 2016). About $80-85 \%$ patients with lung cancer are diagnosed with non-small cell lung cancer (NSCLC) (Chen et al., 2016; Siegel et al., 2018). In recent decades, important progress has been made in the diagnosis and treatment strategies of NSCLC, although there has been no significant improvement in its prognosis, and the 5-year overall survival rate is still $<15 \%$ (Chen et al., 2014). Platinum-based chemotherapy is still the standard-of-care for most patients who suffer from advanced NSCLC (Rossi and Di Maio, 2016). Nevertheless, toxicity, drug resistance, 
and high risk of death are seen clinically, underlining that the medication strategies require to be optimization. There are two types of drug resistance: primary resistance which appertains to chemoresistance prior to chemotherapy, and acquired resistance which emerges following chemotherapy (Kelland, 2007). The common mechanisms of drug resistance mainly include increased drug efflux from cancer cells, reduced uptake of drugs, modification of oncogenes, and inhibition of drug-induced apoptosis (Hamilton and Rath, 2014). Ultimately, the resistance leads to chemotherapy failure and therefore a poor prognosis.

DDP, also known as cisplatinum or cisdiamminedichloroplatinum (II), is a chemotherapeutic drug (Dasari and Tchounwou, 2014). It has been used to treat a variety of solid malignancies, including testicular, ovarian, head and neck, colorectal, bladder, and lung cancers (Gridelli et al., 2015). Cisplatin exerts anticancer effects through multiple mechanisms, but its utmost (and best understood) mode of action involves the generation of DNA lesions followed by the activation of DNA damage response and the induction of mitochondrial apoptosis (Dasari and Tchounwou, 2014). Cisplatin treatment often induces the development of chemoresistance, leading to therapeutic failure and plentiful unfavorable side effects such as serious kidney problems, allergic reactions, declining immunity to infections, gastrointestinal diseases, hemorrhage, as well as hearing loss found particularly in young patients (Dasari and Tchounwou, 2014). Because cisplatin is the main therapeutic option in some clinical settings, the development of chemosensitization strategies has become a clinically significant goal. In addition, combination therapies with cisplatin and other drugs have been taken into high consideration to surmount drug-resistance and lessen toxicity.

Fortunately, natural products with various chemical structures and pharmacological effects can serve as effective drug resistant substances (Thomford et al, 2018). PTL, originally isolated from Tanacetum parthenium L., is a prominent and naturally occurring germacranolide, which has shown cytotoxicity in multifarious human cancer cells but not in normal cells (Ghantous et al., 2013). PJL has been found to have anti-inflammatory (Wang et al., 2016), antioxidant (Farzadfar et al., 2016), and antitumor activity in a variety of cancers, including breas (Araujo et al., 2019), acute myeloid leukemia (Darwish et al., 2019), and non-small cell lung cancer (Zhang et al., 2009).

Despite the anticancer effect of PTL reported previously in several cancer cell lines, the effect of co-treatment with PTL and DDP for synergistic inhibition of NSCLC cells has not been wellexplored. The aim of this study was to investigate the potential synergistical effects of the combination of PTL and DDP on NSCLC as well as the related mechanism.

\footnotetext{
Abbreviations: 2D, two dimensional; CCK8, Cell Counting Kit-8; CI, combination index; CID, compound ID; cisplatin, DDP; ECL, electrochemiluminescence system; Fa, fraction affected; FCM, flow cytometry; HRP, horseradish peroxidase; NSCLC, non-small-cell lung cancer; PI, propidium iodide; PI3K, phosphatidylinositol 3-kinase; PTL, parthenolide; PVDF, polyvinylidenedifluoride; TCM, Traditional Chinese medicine.
}

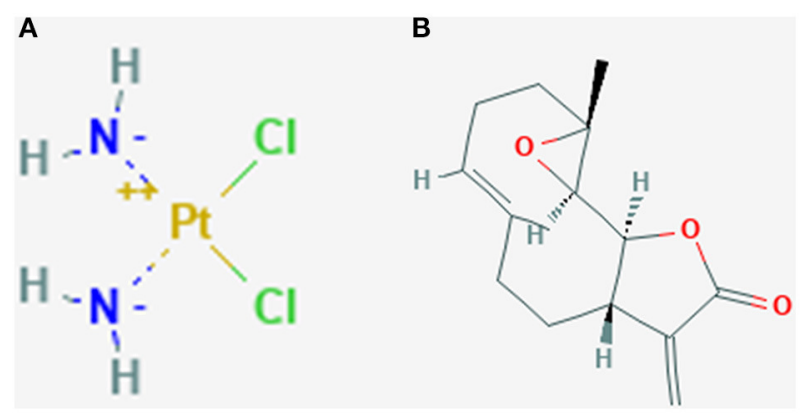

FIGURE 1 | 2D structure of DDP (A) and PTL (B) (obtained from PubChem compound, http://pubchem.ncbi.nlm.nih.gov/).

\section{MATERIALS AND METHODS \\ Reagents, Cell Lines, and Cell Culture}

Parthenolide and cisplatin (Figure 1) were obtained from Santa Cruz Biotechnology (Dallas, USA). A549, PC9, H1299, and BEAS-2B cell lines were generously provided by the State Key Laboratory of Oncology in South China. They were cultivated in RPMI 1640 medium supplemented with $10 \%$ fetal bovine serum, L-glutamine, gentamycin, and penicillin/streptomycin, and cultured at $37^{\circ} \mathrm{C}$ in a humidified atmosphere containing $5 \% \mathrm{CO}_{2}$.

\section{Cell Viability Assay}

Cell viability was evaluated using a Cell Counting Kit-8 (CCK8) assay. Exponentially growing cells were inoculated in 96-well culture plates $(\sim 6,000$ cells/well in $100 \mu \mathrm{L}$ medium), cultivated overnight, and incubated with a series of concentrations of PTL $(0-100 \mu \mathrm{M})$ or DDP $(0-2 \mu \mathrm{M})$ for $48 \mathrm{~h}$. Then $10 \mu \mathrm{L}$ of CCK8 solution was added to each well, the plate was incubated at $37^{\circ} \mathrm{C}$ for $2 \mathrm{~h}$, and the absorbance (A) was measured at $450 \mathrm{~nm}$ on a microplate plate reader (Thermo Scientific, Rockford, IL, USA). The inhibition rate was calculated as follows: (A control - A treated)/A control $\times 100 \%$, where $\mathrm{A}$ treated and $\mathrm{A}$ control are the absorbance of the treated and control cells, respectively.

\section{Calculation of the Combination Effect Index}

The inhibitory effects of PTL and DDP were confirmed by CCK8 assay. We employed the combination index $(\mathrm{Cl})$ depicted by Chou and Talalay for analysis and carried out the analysis by utilizing the CalcuSyn software. $\mathrm{CI}<1$ denotes synergism; $\mathrm{CI}=1$ denotes summation; and $\mathrm{CI}>1$ denotes antagonism.

\section{Wound Healing Assay}

A549 and PC9 cells were plated into 6-well plates $\left(1 \times 10^{6}\right.$ $\mathrm{mL} /$ well). When the cell density was about $90 \%$ after $24 \mathrm{~h}$, serumfree medium was used to starve the cells for $24 \mathrm{~h}$. Confluent monolayer cells were scratched in a straight line using a $100 \mu \mathrm{L}$ pipette tip. The exfoliated cells were cleared with PBS (GIBCO) wash three times. Then the serum free RPMI1640 containing various drugs was used to culture the cells and the cells are 
allowed to heal the wounds for $48 \mathrm{~h}$. At the same place where cells were scratched, pictures (magnification, $10 \times$ ) were taken at 0 and $24 \mathrm{~h}$. Ultimately the Adobe Photoshop CS6 software was used to determine the migration length of cells according to the change of wound size.

\section{Transwell Invasion Assay}

A549 and PC9 cells were incubated in serum-free RPMI1640 for $24 \mathrm{~h}$. Subsequently, cells $(6 \times 104)$ in $600 \mu \mathrm{L}$ serumfree medium containing various drugs were plated on the top compartment of transwell filters, which were covered by thin layers of matrigel basement membrane matrix, with $700 \mu \mathrm{L}$ medium containing $10 \%$ FBS in the bottom compartment. The transwell filters were cultured at $37^{\circ} \mathrm{C}$ with $5 \% \mathrm{CO}_{2}$ for $48 \mathrm{~h}$. After that, the cells adhering to the bottom membrane were fixated in $4 \%$ paraformaldehyde for $30 \mathrm{~min}$, and subsequently dyed with $0.5 \% \mathrm{CV}$ solution for $15 \mathrm{~min}$ at room temperature. Ultimately, the transwell filters were inverted and observed under a microscope (magnification, $100 \times$ ) for photographic recording and the number of cells on the bottom surface was counted. Five random fields were counted per filter in all groups.

\section{Cell Colony Formation Assay}

Cells were trypsinized single cells were obtained and seeded in 6well plates at a density of 500 cells/well. After 10 days of culture, colonies were fixed with methyl alcohol and stained with crystal violet, and the colony formation ratio was calculated.

\section{Cell Cycle Distribution Analysis}

A Cell Cycle Detection Kit obtained from 4A Biotech Co., Ltd. (Beijing, China) was employed to detect the cell cycle distribution. Briefly, A549 and PC9 cells were inoculated in six-well plates $\left(1 \times 10^{6}\right.$ cells/well $)$ and cultured overnight, and then cells were incubated with PTL or DDP alone or in combination for $48 \mathrm{~h}$. After that, cells were rinsed with cold phosphate-buffered saline (PBS) and immobilized with 70\% ethyl alcohol overnight. After washes with PBS, cells were stained with propidium iodide $(10 \mu \mathrm{g} / \mathrm{mL})$ in the presence of RNase $(1 \mathrm{~g} / \mathrm{L})$, $1 \mathrm{~g} / \mathrm{L}$ sodium citrate, and $0.5 \%$ Triton $\mathrm{X}-100(\mathrm{v} / \mathrm{v})$ in the dark for $30 \mathrm{~min}$. Then cells were collected for cell cycle distribution analysis using an ACEC NovoCyte flow cytometer equipped with Novoexpress (Becton Dickinson, San Jose, CA, USA).

\section{Cell Apoptosis Analysis}

An Annexin V-FITC apoptosis detection kit obtained from 4A Biotech Co., Ltd. (Beijing, China) was used to detect cell apoptosis. A549 and PC9 cells were seeded in six-well plates and cultured overnight. After exposure to PTL or DDP alone or in combination for $48 \mathrm{~h}$, the cells were harvested, resuspended in $500 \mu \mathrm{L}$ of incubation buffer containing Annexin V-FITC and PI, and incubated for $30 \mathrm{~min}$ in the dark. The cells were then washed and subjected to apoptosis analysis using an ACEC NovoCyte flow cytometer furnished with Novoexpress.

\section{Xenograft Tumor Assay in Nude Mice}

Nude female BALB/c-nu/nu mice (4-6 weeks) were obtained from the Institute of Laboratory Animal Sciences, Chinese Academy of Medical Sciences, Beijing, China, and placed in a specific pathogen-free $(\mathrm{SPF})$ environment. A549 cells $\left(3 \times 10^{6}\right)$ in $0.2 \mathrm{~mL}$ of PBS were inoculated into the flanks of the mice. When tumors became palpable, mice were subdivided into four groups of six. Figure 7A shows the in vivo treatment regimen with a variety of concentrations of PTL or DDP. PTL and vehicle control were administrated daily via intraperitoneal (I. P.) injection, while DDP was administrated every 5 days via I. P. injection. The tumor volumes were measured at the beginning of the treatment and every 4 days during treatment by measuring the length (L) and width $(\mathrm{W})$ of the tumors. The tumor volume was calculated by the following formula: $v=$ length $\times(\text { width })^{2} / 2$. Tumors were excised and weighed on the second day after the last injection. All experiments were approved by the Institutional Animal Care and Use Committee of Sun Yat-sen University and performed in accordance with national ethical guidelines.

\section{Potential Target Identification Based on Pharmmapper}

PharmMapper (http://lilab.ecust.edu.cn/pharmmapper/index. php) consists of a huge internal repertoire of a pharmacophore database, which is pullec out from all the targets in TargetBank, DrugBank, BindingDB, and PDTD. PhamMapper stores and accesses over 7,000 receptor-based pharmacophore models (information about 1,627 drug targets can be found, and 459 of which are human protein targets). First, the SDF format of PTL was downloaded from PubChem Compound (https:// www.ncbi.nlm.nih.gov/pccompound/) and then uploaded to PharmMapper. After exactly setting the parameters, target recognition was performed, and the information relating to the frrst 300 potential protein targets was acquired.

\section{Bioinformatics and Network Pharmacology Analysis}

Based on the DAVID database (https://david.ncifcrf.gov/), we imported the top 300 potential targets, selected Homo sapiens, and then carried out Gene Ontology (GO) analysis and Kyoto Encyclopedia of Genes and Genomes (KEGG) pathway enrichment analysis. The information associated with the first 100 potential pathways was acquired. A parameter enrichment gene count $\geq 2$ and hypergeometric analysis were used for testing significance threshold with a $P<0.05$. For a KDR value $<0.05$ (Q), we selected the Top 20 pathway, and mapped senior bubbles by the OmicShare website (http://www.omicshare.com/).

\section{Western Blot Analysis}

Cells were harvested and processed in RIPA lysis buffer supplemented with $1 \%$ phenylmethanesulfonyl fluoride and $1 \%$ phosphatase inhibitor. The soluble protein fractions were extracted after centrifugation at $1.35 \times 10^{4} \mathrm{~g}$ for $10 \mathrm{~min}$. The protein concentrations were tested using a BCA kit. Around $30 \mathrm{mg}$ of proteins were separated by $8-12 \%$ sodium dodecyl sulfate-polyacrylamide gel electrophoresis (SDS-PAGE), transferred to PVDF membranes, and incubated with different primary antibodies overnight at $4^{\circ} \mathrm{C}$. Membranes were then washed and incubated with proper secondary antibodies. Signals were detected using an ECL chemiluminescence detection kit. 


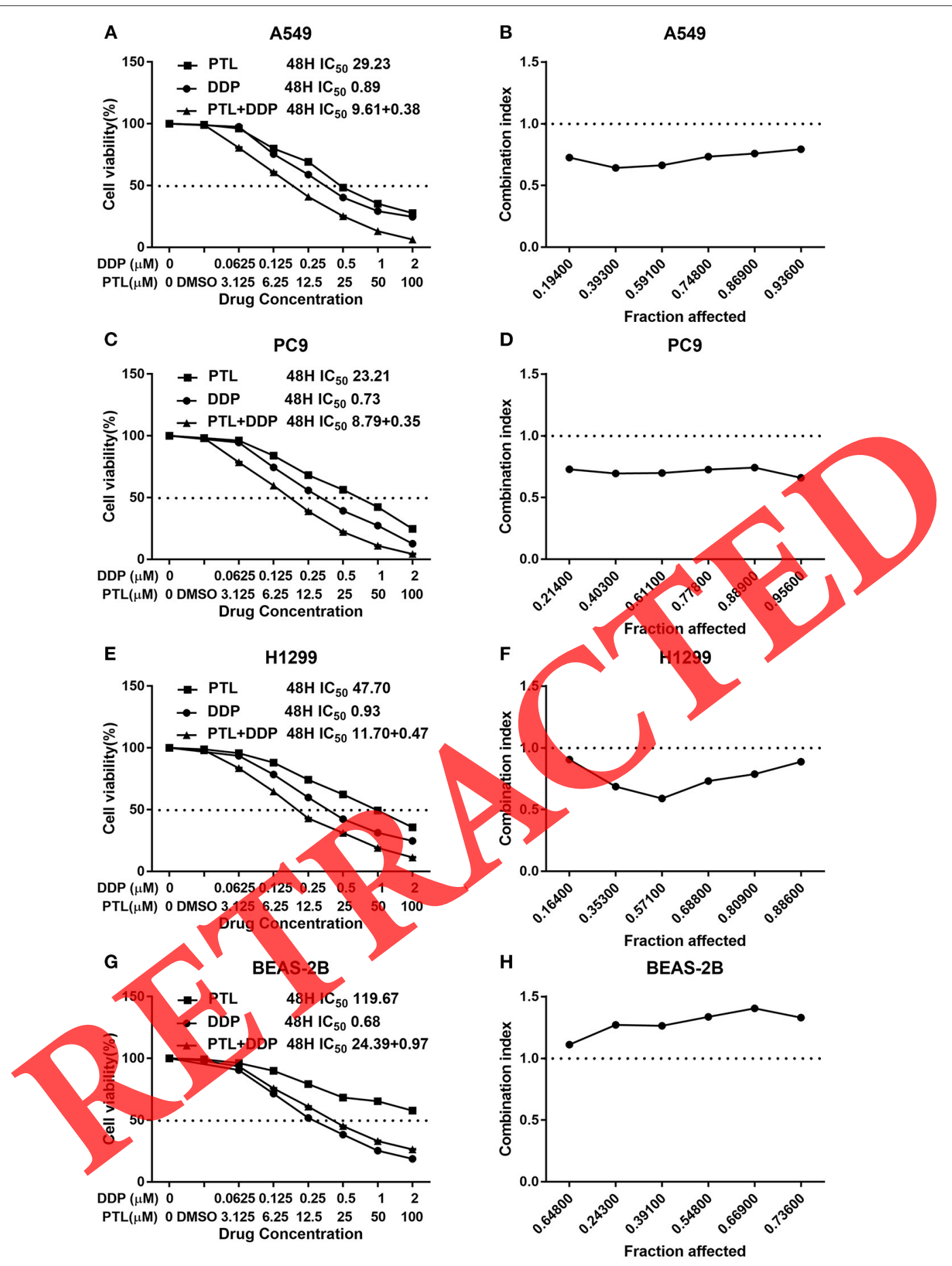

FIGURE 2 | Proliferative inhibitory effect of PTL, DDP, and the combination treatment on NSCLC cells. Drug concentration-cell viability curves were generated as the viable cell percentage based on the cell viability assay (A,C,E,G). Synergistic effects between PTL and DDP are presented as Fa-Cl plots (B,D,F,H). Data are from three repeated experiments with quadruplicate wells (mean $\pm S D$ ).

\section{Statistical Analysis}

SPSS 24.0 software (IBM, NY) was employed to performed statistical analysis. Statistical comparisons were performed through independent samples $t$-test or one-way analysis of variance (ANOVA). Data measurements are indicated as mean values \pm standard deviation. The value of $p<0.01$ was considered statistically significant. 


\section{RESULTS}

\section{Co-treatment With PTL and DDP Concurrently Inhibited the Proliferation of NSCLC Cells}

It was observed that both PTL and DDP inhibited the proliferation of NSCLC cells in a dose-dependent manner. After $48 \mathrm{~h}$ treatment with PTL, the $\mathrm{IC}_{50}$ values were 29.423, 23.21, 47.70, and $119.67 \mu \mathrm{M}$ for A549, PC9, H1299, and BEAS-2B cell lines, respectively. Similarly, the $\mathrm{IC}_{50}$ values obtained after DDP treatment were $0.89,0.73,0.93$, and $0.68 \mu \mathrm{M}$ for A549, PC9, H1299, and BEAS-2B cell lines, respectively (Figure 2). We also treated the cell lines with a combination of PTL and DDP (the PTL:DDP molar ratio of 50:1) for $48 \mathrm{~h}$. The results showed that, when compared with single drug therapy, the combination drug

TABLE 1 | Summary of $\mathrm{Cl}$ value and the concentration of separate drugs in combination at $50 \% \mathrm{Fa}$.

\begin{tabular}{lcccc}
\hline \multirow{2}{*}{ Drug combination } & \multicolumn{4}{c}{ Fa $=\mathbf{0 . 5}$} \\
\cline { 2 - 5 } & A549 & PC9 & H1299 & BEAS-2B \\
\hline $\mathrm{DDP}+\mathrm{PLT}$ & & & & \\
$\mathrm{Cl}$ & 0.69832 & 0.71184 & 0.74952 & 1.71719 \\
$\mathrm{DDP}(\mu \mathrm{M})$ & 0.38906 & 0.35321 & 0.48497 & 0.44289 \\
$\mathrm{PLT}(\mu \mathrm{M})$ & 9.72652 & 8.83035 & 12.1244 & 11.0722 \\
& & &
\end{tabular}

therapy had a stronger inhibitory effect on cell proliferation. The synergistic effects of drug combination therapy were observed in the A549, PC9, and H1299 cell lines with different Fa values, but not in the BEAS-2B cell line. Table 1 lists the summary of the $\mathrm{CI}$ and the concentrations of the individual drugs used in combination at $50 \% \mathrm{Fa}$.

\section{Cooperation of PTL and DDP Synergistically Suppressed the Migration and Invasion of NSCLC Cells}

We used wound healing assay and transwell assay to evaluate the effects of individual PTL and DDP or combination of these two drugs on the migration and invasion of A549 and PC9 cells. Figure 3 shows that both the migration distances and invaded cell numbers were reduced markedly after $48 \mathrm{~h}$ treatment with either individual drugs or a combination of PTL and DDP. Furthermore, the combination treatment resulted in the smallest values for both migration distance and aggressive cell number, suggesting the combination of PTL and DDP exerted a more significant inhibition on cell migration and inyasion than each of them alone.

\section{Co-treatment With PTL and DDP Coordinately Inhibited the Cell Colony Formation of NSCLC Cells}

As showed in Figure 4, compared with untreated controls, PTL, DDP, and the combination of them all significantly inhibited

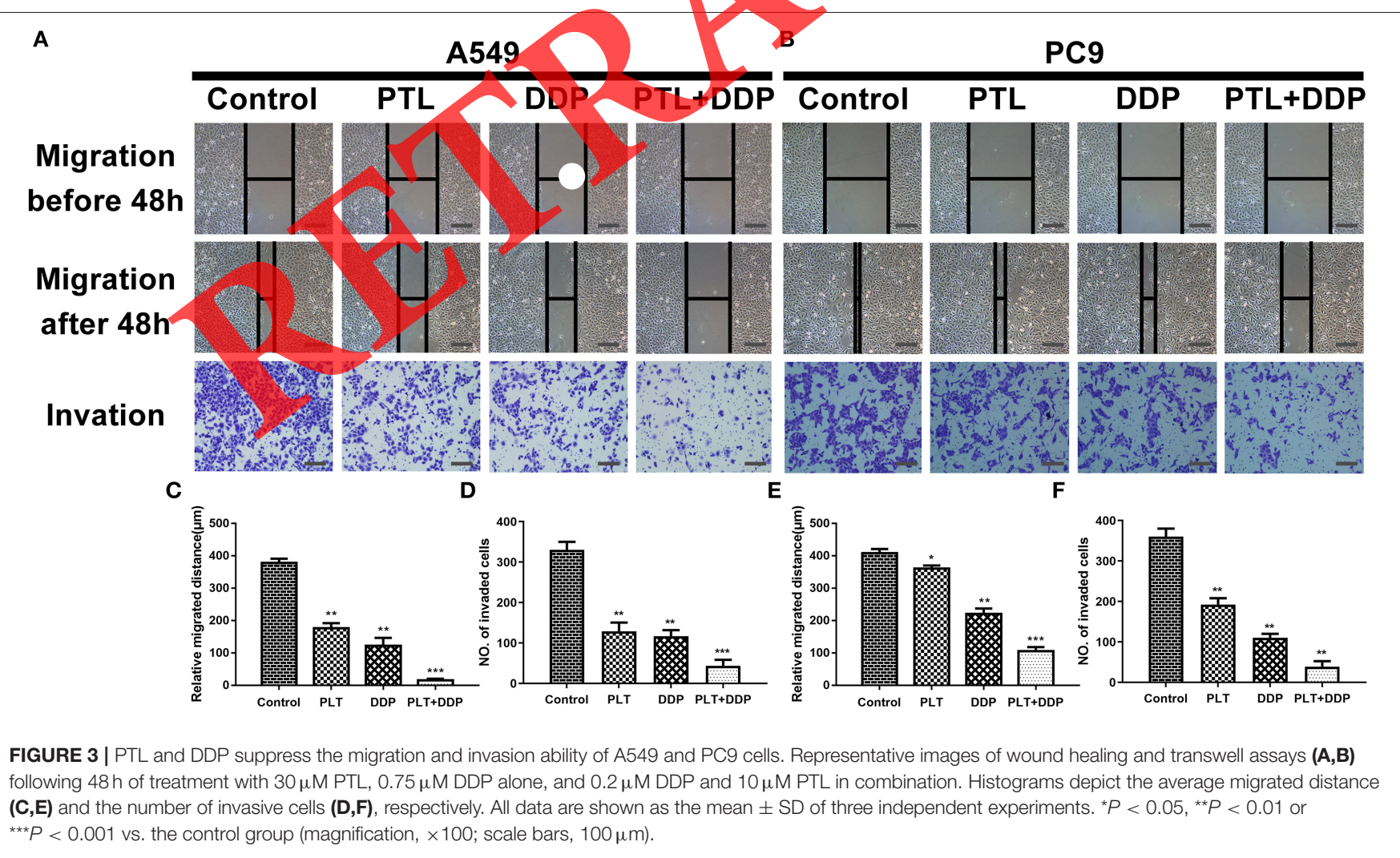




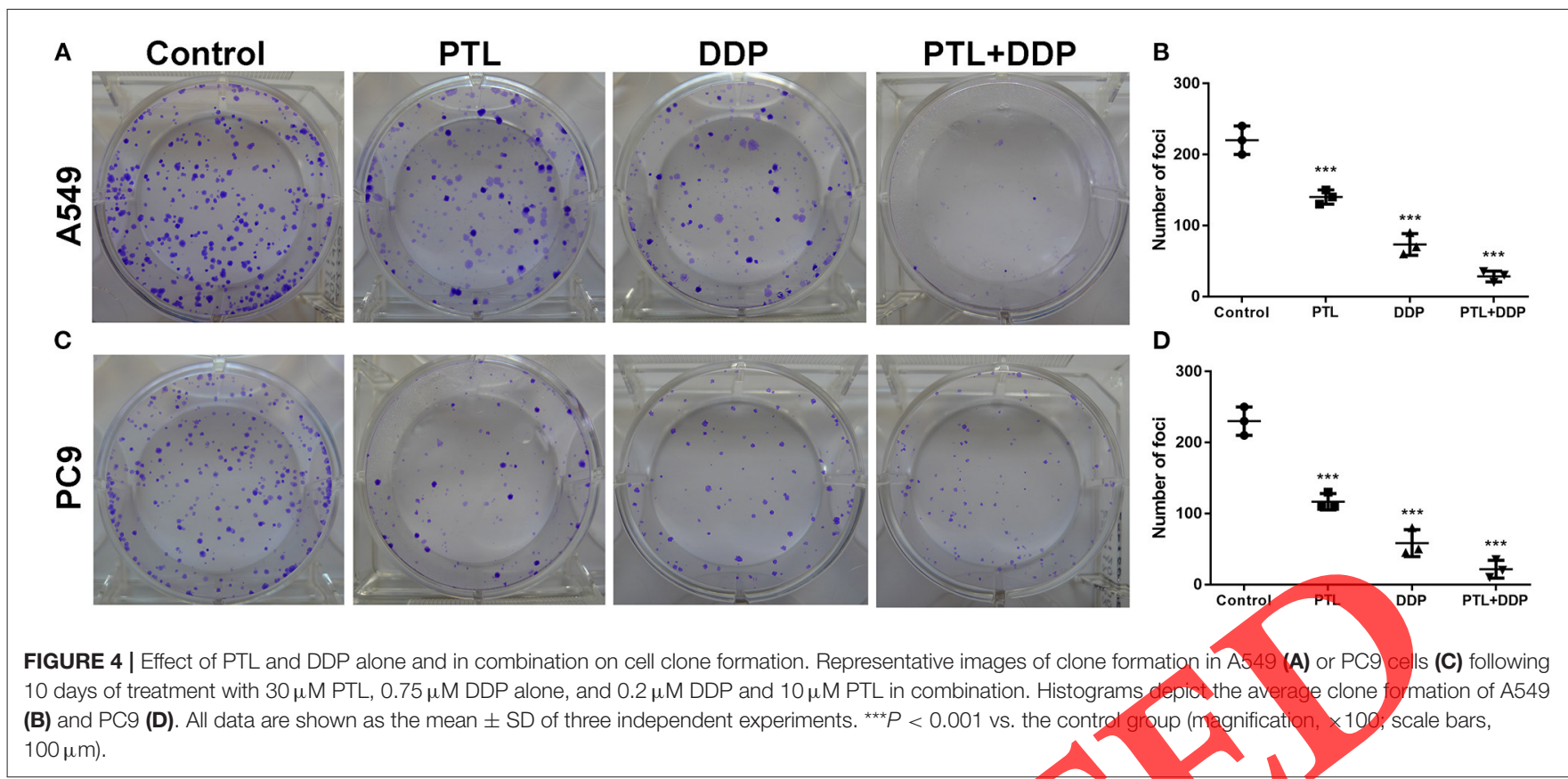

cell colony formation of A549 and PC9 cells. Similarly, the combination of PTL and DDP exerted a more significant inhibition on cell colony formation than each of them alone.

\section{Co-treatment With PTL and DDP Synergistically Arrested the Cell Cycle of NSCLC Cells}

After verifying the anti-proliferative effect of PTL and DDP, flow cytometry (FCM) was used to analyze the cell cycle of the treated NSCLC cells. As illustrated in Figure 5, PTL and DDP both arrested A549 and PC9 cells at S and G2 phases, while the combination of PTL and DDP showed a more significant effect in arresting PC9 cells at S and 62 phases

\section{Co-treatment With PTL and DDP Synergistically Induced Apoptosis in NSCLC Cells}

As shown in Figure 6, both the PTL and DDP individual drug treatments and the drug combination enhanced the ratio of early and late apoptosis in A549 and PC9 cells. Additionally, the combination of PTL and DDP was more efficient at inducing apoptosis compared to the single treatment (PTL + DDP vs. PTL, $p=0.0004 ;$ PTL + DDP vs. DDP, $p=0.0006)$.

\section{Co-treatment With PTL and DDP Synergistically Suppressed A549 Cell Xenograft Tumor Growth}

Figure 7 shows the experimental setup of the in vivo animal experiment, including A549 cell seeding and drug treatment. Our next step was to study the effects of PTL and DDP on the growth of xenograft NSCLC tumors. It was found that the xenograft tumors in the control group grew faster than those in the group treated with the tested drugs. In addition, compared with PTL and DDP monotherapy, the combination of PTL and DDP had a more significant inhibitory effect on tumor growth (PTL + DDP vs. PTL $p=0.004$; PTL + DDP vs. DDP, $p=0.005)$. These results indicated that the anti-tumor effect of DDP in vivo could be effectively enhanced by PTL.

\section{Potential Target Proteins of PTL and the Bioinformatics and Network Pharmacology Analysis}

The relevant information of the first 300 potential protein targets of PTL was obtained utilizing PharmMapper (Table 2). We conducted gene ontology (GO) analysis and Kyoto Encyclopedia of Genes and Genomes (KEGG) pathway enrichment analysis according to the DAVID database (https://david.ncifcrf.gov/). The obtained bioinformatics analysis was depicted in Figure 8, suggesting that PTL might play a role, mainly through affecting the PI3K/Akt signaling pathway.

\section{The Combination of PTL and DDP Synergistically Inhibited the Activity of the PI3K/Akt Signaling Pathway in NSCLC Cells}

Western blotting analysis demonstrated that both drug monotherapy and combination therapy increased the expression levels of Bax and cleaved Caspase-3, but decreased the expression levels of p-PI3K, p-Akt, Caspase-3, and Bcl-2, with total expression levels of Akt, PI3K, and glyceraldehyde 3-phosphate dehydrogenase remaining unchanged. Importantly, the efficacy of drug combination treatment was more significant than the single drug treatments (PTL + DDP vs. PTL, $p<0.01$ PTL + DDP vs. DDP, $p<0.01)$. Moreover, the inhibitory effect of 


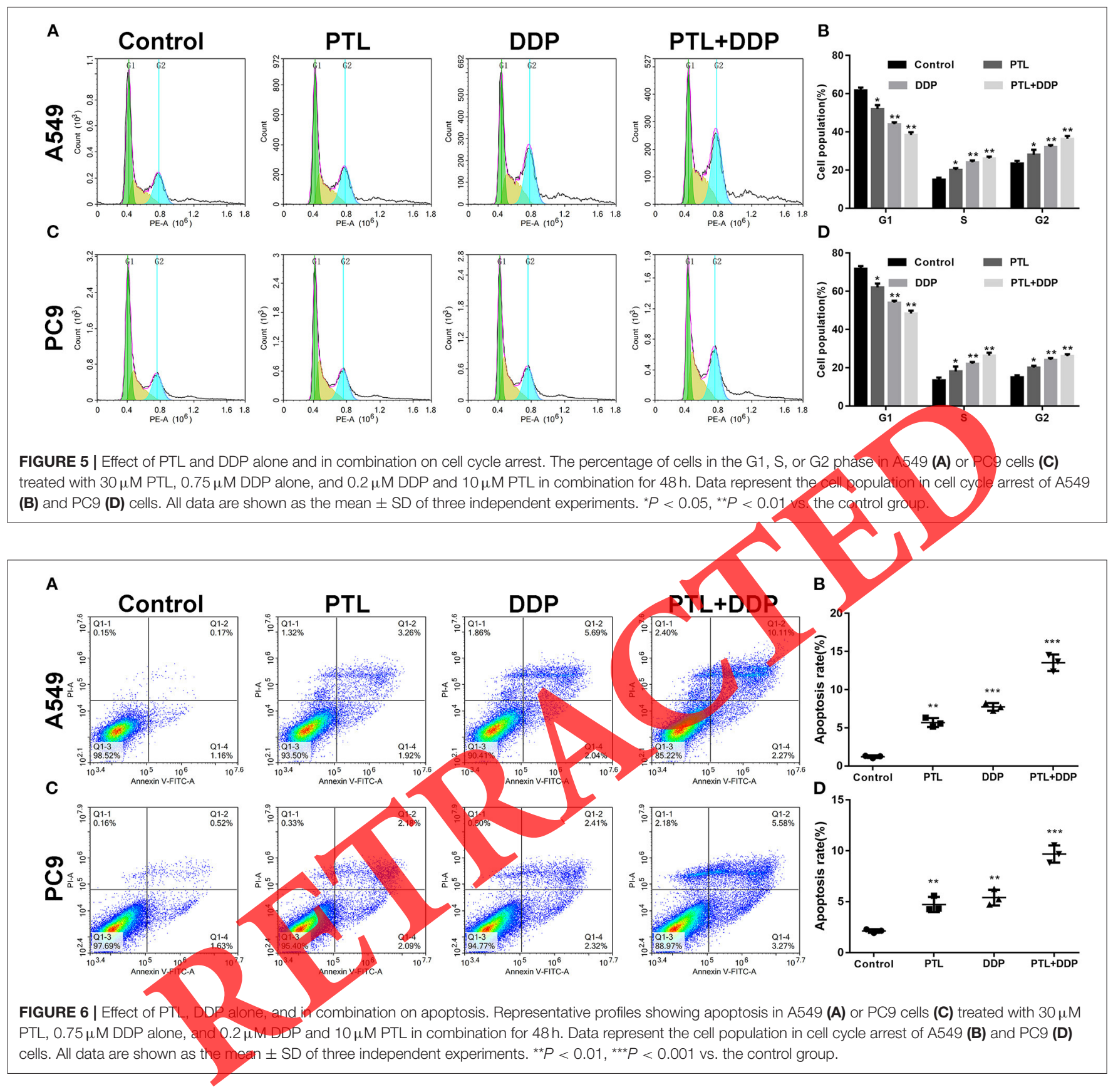

PTL + DDP combined treatment on the signaling pathway was partially restored by a PI3K activator (740 Y-P), as shown in Figure 9 ( $p<0.01$ for $\mathrm{p}-\mathrm{PI} 3 \mathrm{~K}$, p-Akt, Caspase-3, Bcl-2, Bax, and cleaved Caspase- 3 between 740 Y-P + PTL + DDP and PTL+ DDP groups).

\section{DISCUSSION}

In the process of tumor chemotherapy, one of the toughest problems is that cancer cells develop resistance to chemotherapy drugs. Despite the fact that cisplatin-based chemotherapy is the first-line therapy for NSCLC, the occurrence of acquired resistance to cisplatin still presents a great challenge (Dasari and Tchounwou, 2014; Rossi and Di Maio, 2016). The development of cisplatin resistance is a key issue in the failure of NSCLC therapy, and can lead to cancer palindromia and metastasis.

Artemisinin (qinghaosu) and arsenic oxide (III) $\left(\mathrm{As}_{2} \mathrm{O}_{3}\right)$ have achieved remarkable success in clinical practice, and have attracted the attention of many researchers to natural extracts. Considering their safety, long-term use, and ability to target various pathways, there has been great interest in reunderstanding the molecular mechanisms of their activities. In the clinical practice, many traditional Chinese medicines have shown synergistic effects in chemotherapy. 
A

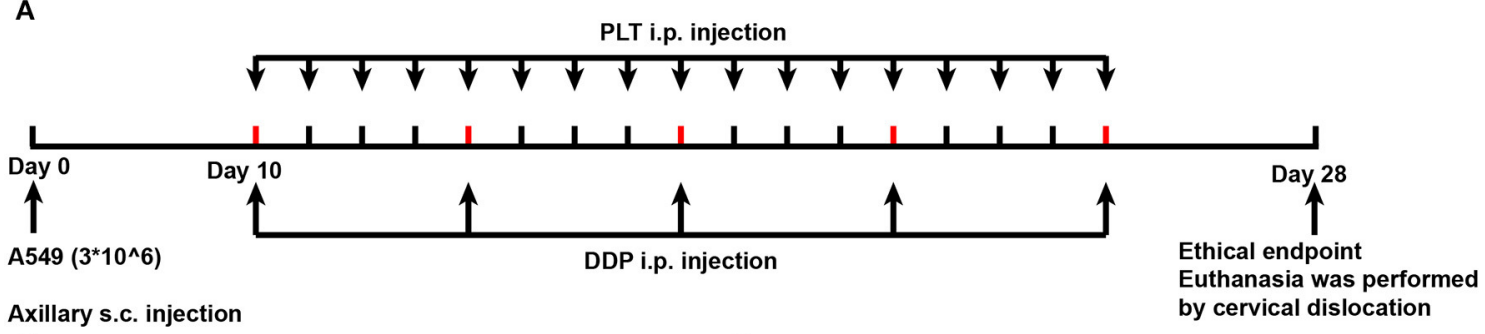

B

C
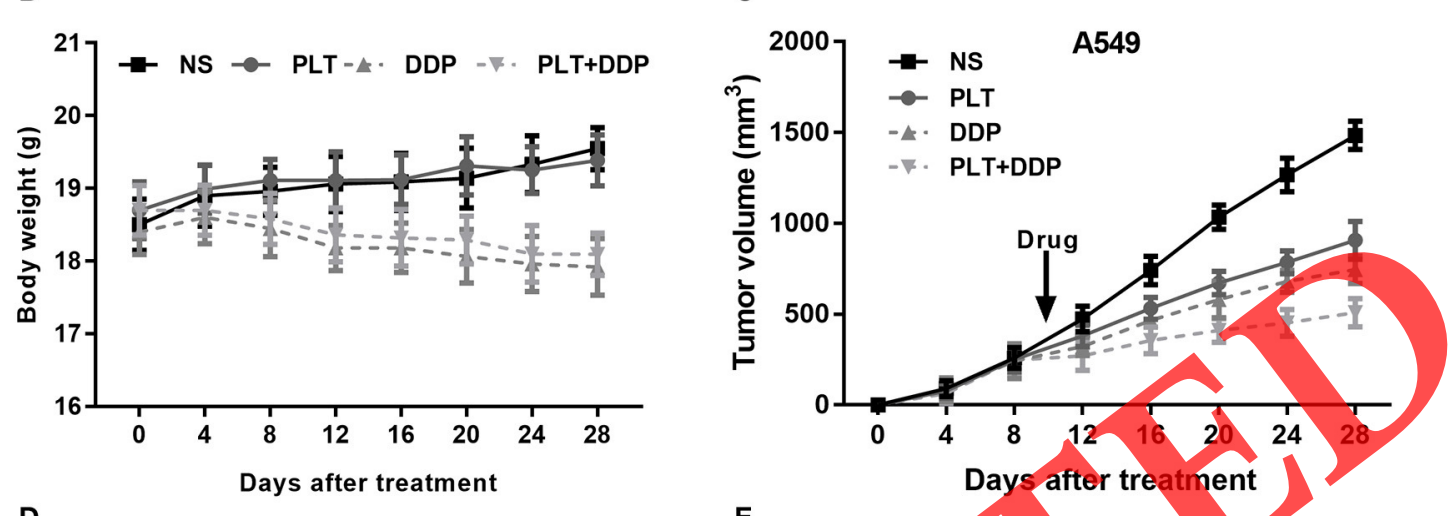

D

E
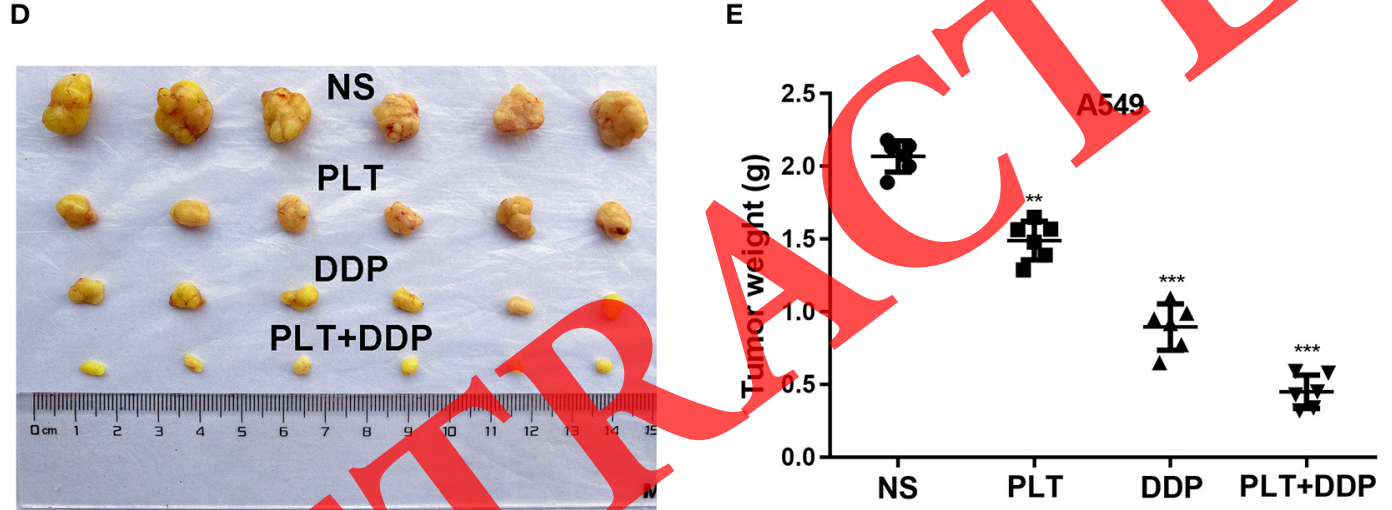

FIGURE 7 | PTL combined with DOP inhibits NSCLC xenograft umor growth. Time line of NSCLC cell inoculation and drug treatment (A). Time courses of animal weight (B). The tumor volume of all groups was measured every 4 days, beginning the first day after injection until the study end point (C). Tumors derived from A549 cells in six male nude mice are presented (D). The tumbr weight of all groups was measured and compared, ${ }^{\star \star *} P<0.001$ vs. the control group (E). Data are presented as mean 1 SD. ${ }^{\star \star} P<0.01$ or ${ }^{\star \star} \mathrm{P}<0,001 . N=5$ in each group.

In recent years, PTL has shown the ability to comprehensively prevent tumor progression, such as the prevention of NSCLC through the induction of apoptosis. Although PTL has been reported to have anti-tumor ability, the mechanism by which it inhibits tumorigenesis remains unclear. Therefore, to fully explain its biological activity on different types of cancer, including NSCLC, will require further research. According to modern pharmacological research, the combined application of two drugs could inhibit the growth, proliferation, migration, and invasion of a variety of tumor cells, as well as induce tumor cell apoptosis and inhibit the effect of tumor-promoting substances on potential tumor cells. In this study, we found that the combined use of PTL and DDP had a synergistic effect on NSCLC. This can be considered as a new adjuvant treatment strategy for NSCLC.

Some recent studies have also provided evidence that PTL could act against many varieties of cancers, such as NSCLC (Talib and Al Kury, 2018) and breast cancer (Araujo et al., 2019; Berdan et al., 2019). Nevertheless, there is a lack of evidence at both cellular level and in animal models to show the effect of PTL and DDP combination on the development of NSCLC. This study revealed that PTL combined with DDP had an inhibitory effect on the growth and metastasis of NSCLC and the PI3K/Akt pathway, providing a potential basis for the promising strategy of PTL and DDP combination for the treatment of NSCLC.

According to the $\mathrm{IC}_{50}$ values analyzed using CCK8 assay, we proved that PTL and DDP could inhibit the proliferation of A549, 
TABLE 2 | Potential targets of parthenolide by PharmMapper.

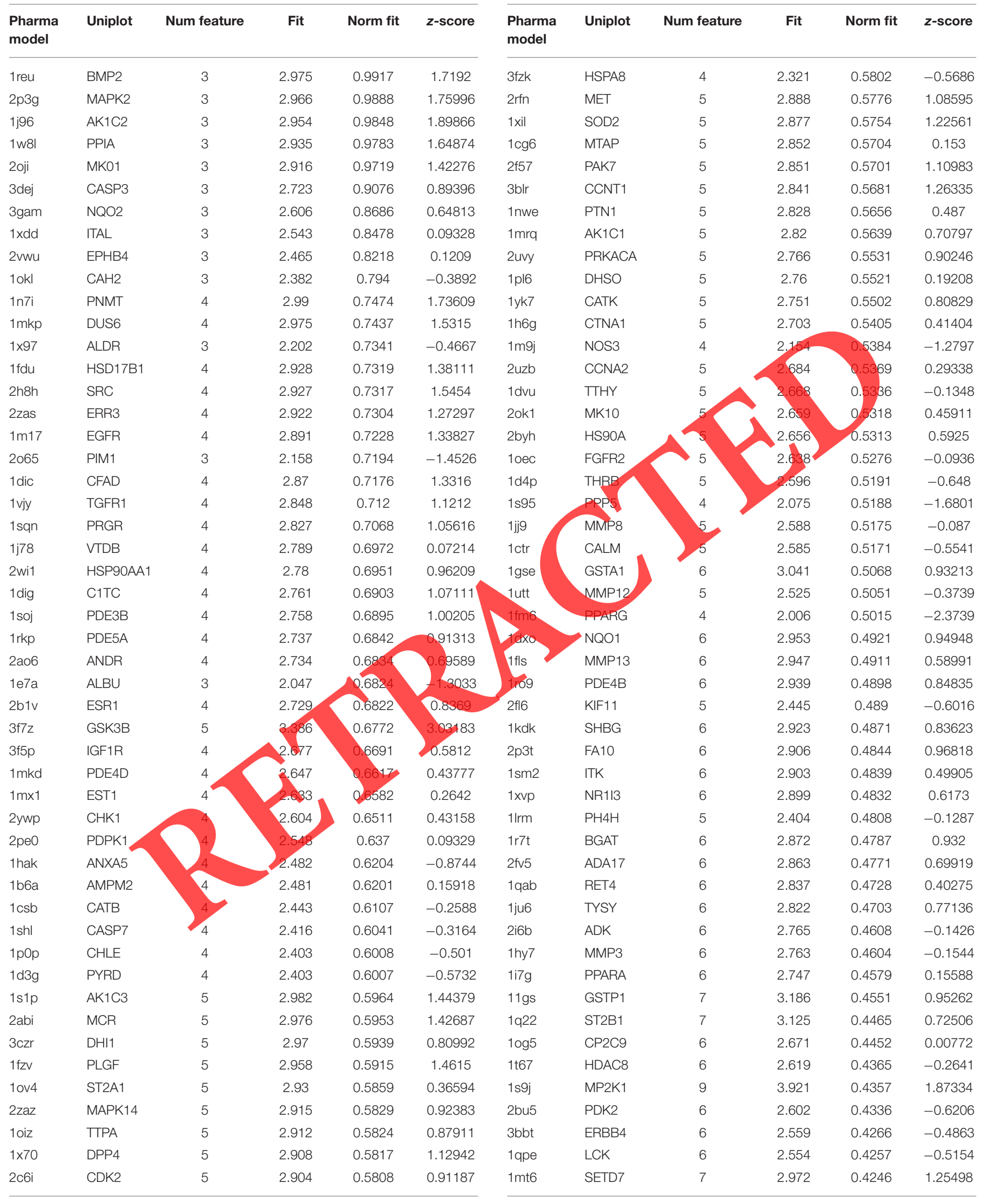


TABLE 2 | Continued

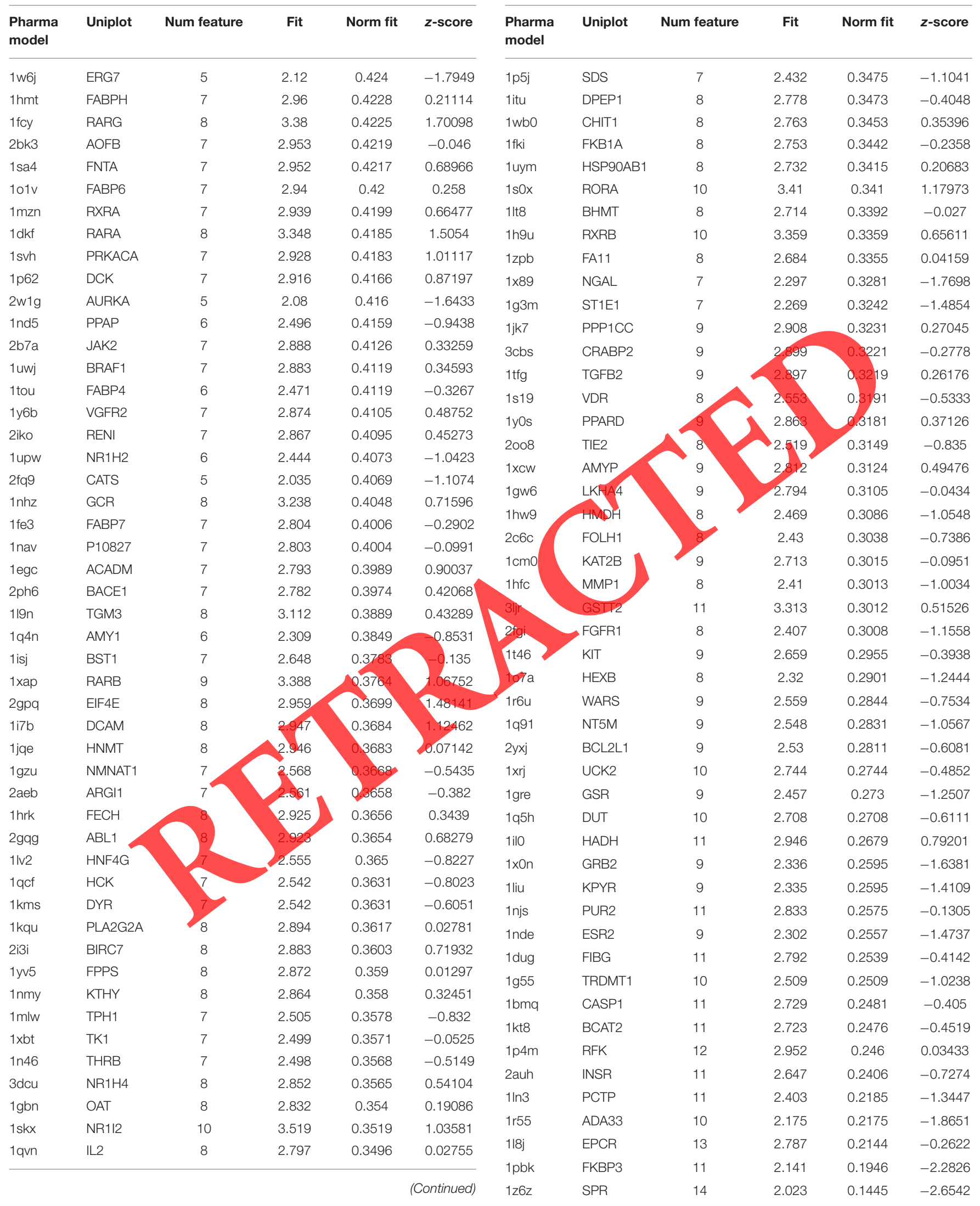

TABLE 2 | Continued 
PC9, and H1299 cells in a dose-dependent and time-dependent manner. In comparison with PTL, DDP had a stronger inhibitory effect on the tested cell line when treated as a single agent. The combination of drugs exerted a synergistic inhibitory effect on A549, PC9, and H1299 cells. Based on the above results, we proposed the hypothesis that PTL may increase the sensitivity of NSCLC to DDP.

Furthermore, PTL can not only inhibit hypoxia-inducible factor- $1 \alpha$ signaling transduction in colorectal cancer, but could also inhibit hypoxia induced epithelial-mesenchymal transition (Kim et al., 2017). As suggested by our findings, the combination of PTL and DDP could synergistically suppress the migration and invasion ability of A549 and PC9 cells.

In addition, this study analyzed the mechanism of the synergistic effect of PTL and DDP on cell cycle distribution in A549 and PC9 cells using FCM. The results indicated that PTL, DDP, and combined treatment caused S and G2 phase arrest in A549 and PC9 cells. Tang found that PTL treatment inhibited survivin, arrested cancer cells at G2/M phases, and triggered cell death in human malignant glioblastoma cells (Tang et al., 2015). However, there is still a controversy in terms of the effect of PTL on cell cycle distribution. One study using human uveal melanoma cells discovered diverse outcomes that PTL exerted growth-inhibiting and apoptosis-inducing effects in UM cells by blocking G1 phase and regulating the mitochondrial pathway (Che et al., 2019). These findings showed that PTL may be conducive to cell cycle arrest at G1 phase in human uveal melanoma cells, while PTL might lead to $\mathrm{G}_{2} / \mathrm{M}$ phase cell cycle arrest in human malignant glioblastoma cells, both of which necessitate further discussion.

Numerous studies have showed that PTL suppresses tumorpromoting effects of nicotine in lung cancer through inducing p53-dependent apoptosis (Talib and $\mathrm{Al}$ Kunt 2018), adjusts mitochondrial autophagy induced by oxidative stress, and plays an inhibitory role in the apoptosis of C2C12 myoblasts vio the p53 signaling pathway (Ren et al 2019). Our study also revealed that, in A549 and PC9 cells, the same results were achieved with both PTL and DDP, and that apoptosis rates could be improved remarkably with their combined application rather than with monotherapy. Qverall, these results indicated that apoptosis could be synergistically promoted by a combination treatment of PTL and DDP.

Moreover, PTL was discovered to induce intrinsic apoptosis in thyroid carcinoma cells both in vivo and in vitro by Li C's team (Yang et al., 2019). Our research showed that both PTL and DDP could suppress the growth of NSCLC xenograft tumors, and that more significant effects were observed with their combination in vivo. As a result, our results showed that the anti-tumor effect of DDP could be effectively enhanced by PTL in vivo. Because of lack of funds, the number of animals we were able to experiment on was limited. Therefore, we did not have different (i.e., less frequent) Schedules of Administration.

Next, the relevant information of the first 300 potential protein targets of PTL was acquired utilizing PharmMapper (Wang et al., 2017). Due to the KEGG pathway analysis, we realized that PTL, in line with recent studies, may chiefly affect the PI3K/Akt signaling pathway (Jeyamohan et al., 2016;
Yang et al., 2019). Likewise, according to numerous current investigations, the chemosensitivity of NSCLC cells to DDP could be increased through the inactivation of the PI3K/Akt pathway (Chen et al., 2017; Shi et al., 2017; Gong et al., 2018; Liu et al., 2018; Xia et al., 2018; Zhao et al., 2018). We therefore speculated that PTL may improve the anti-tumor ability of DDP in NSCLC by obstructing the PI3K/Akt pathway.

There are various cellular processes such as survival, proliferation, growth, metabolism, angiogenesis, and metastasis that can be regulated by the hyperactivated or altered $\mathrm{PI} 3 \mathrm{~K} / \mathrm{Akt} / \mathrm{mammalian}$ target in the rapamycin (mTOR) signaling pathway in many cancer types (Katso et al., 2001; Engelman et al., 2006; Martini et al., 2014). The development of cancer resistance to anticancer therapies is closely related to the activation of the PI3K/AKT/mTOR pathway in several tumor types (Martini et al., 2014). PI3Ks are a group of lipid kinases related to the plasma membrane and are composed of three subunits, the p 85 regulatory subunit, the p55 regulatory subunit, and the p110 catalytic subunit (Donahue et al., 2012). Based on their diverse structures and particular substrates, PI3Ks are classified into three classes: I, II, and IL (Hennessy et al. 2005 Engelman et al., 2006; Martini et al. 2014; Asat et a1., 2016). Over the past few decades, the PI3K pathway has been thought to be deregulated in multiple human cancers, inclucing NSCLC (Dillon et al., 2007). The PIJK pathway is inaetivated by various mechanisms, including the tumor suppressor PTEN, variation or expansion of PI3K, and activation of the upstream tyrosine kinase growth factor receptor or oncogene of PI3K (Stemke-Hale et al., 2008). It was found that overactivity of the PI3K signaling pathway was significantly correlated with the progression of human tumors, increased tumor microvascular density, chemotaxis, and enhanced invasion of cancer cells. Therefore, the PI3K signaling pathway has been considered one of the main targets for cancer therapy (Hennessy et al., 2005; Dillon et al., 2007). Great efforts have been made to develop drugs targeting the PI3K signaling pathway, with many presently being evaluated in clinical tests (Aziz et al., 2009). The suppression of PI3K signaling is a promising and valid means for the treatment of NSCLC.

Through Western blotting, we found that drug treatment resulted in a significant increase in the expression levels of cleaved Caspase- 3 and Bax, but the expression levels of Bcl-2, Caspase3 , p-Akt and p-PI3K proteins were lower, and total Akt and PI3K protein expression remained unchanged. In comparison with single-agent therapy, the combination treatment exhibited a greater effect. Therefore, we proposed a hypothesis that the drug-induced pro-apoptotic process may be related to the downregulation of the PI3K/Akt signaling pathway. In keeping with numerous other research studies, our findings suggested that based on the upregulation of Bax and cleaved Caspase3 , the mitochondrial apoptotic pathway was related to PTLinduced A549 cell death. Unfortunately, we have not validated studies from other perspectives, such as whether AKT inhibition reproduces the effect of PTL on DDP sensitivity, and there remains a lack of further study of the upstream mechanisms of AKT.

The above studies showed that inhibiting the PI3K/Akt signaling cascade could be considered an effective strategy for 


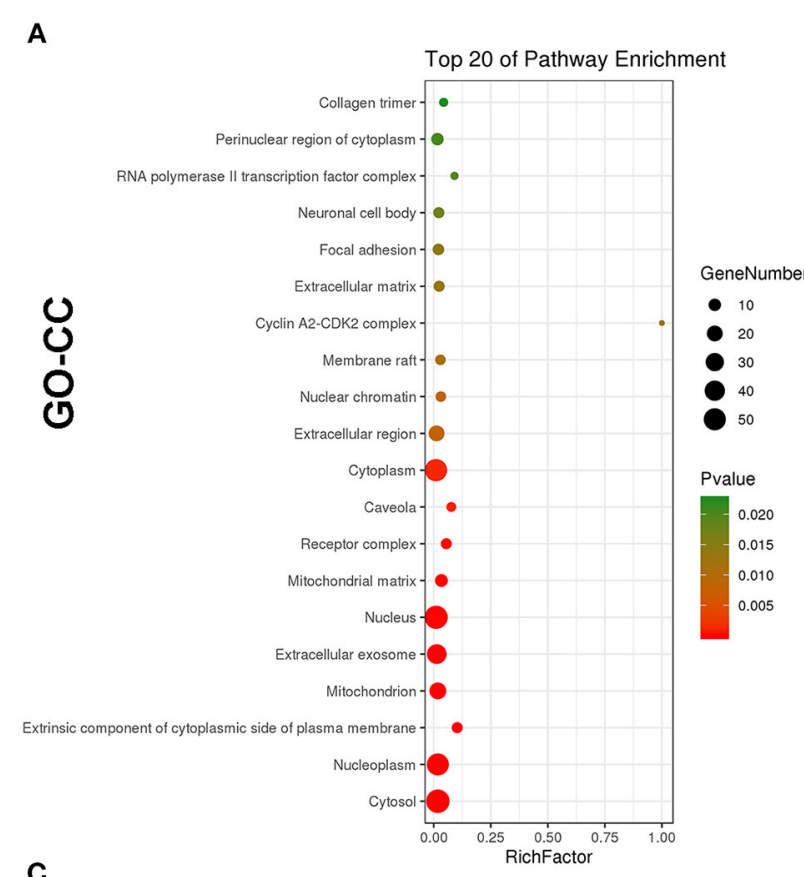

B

C
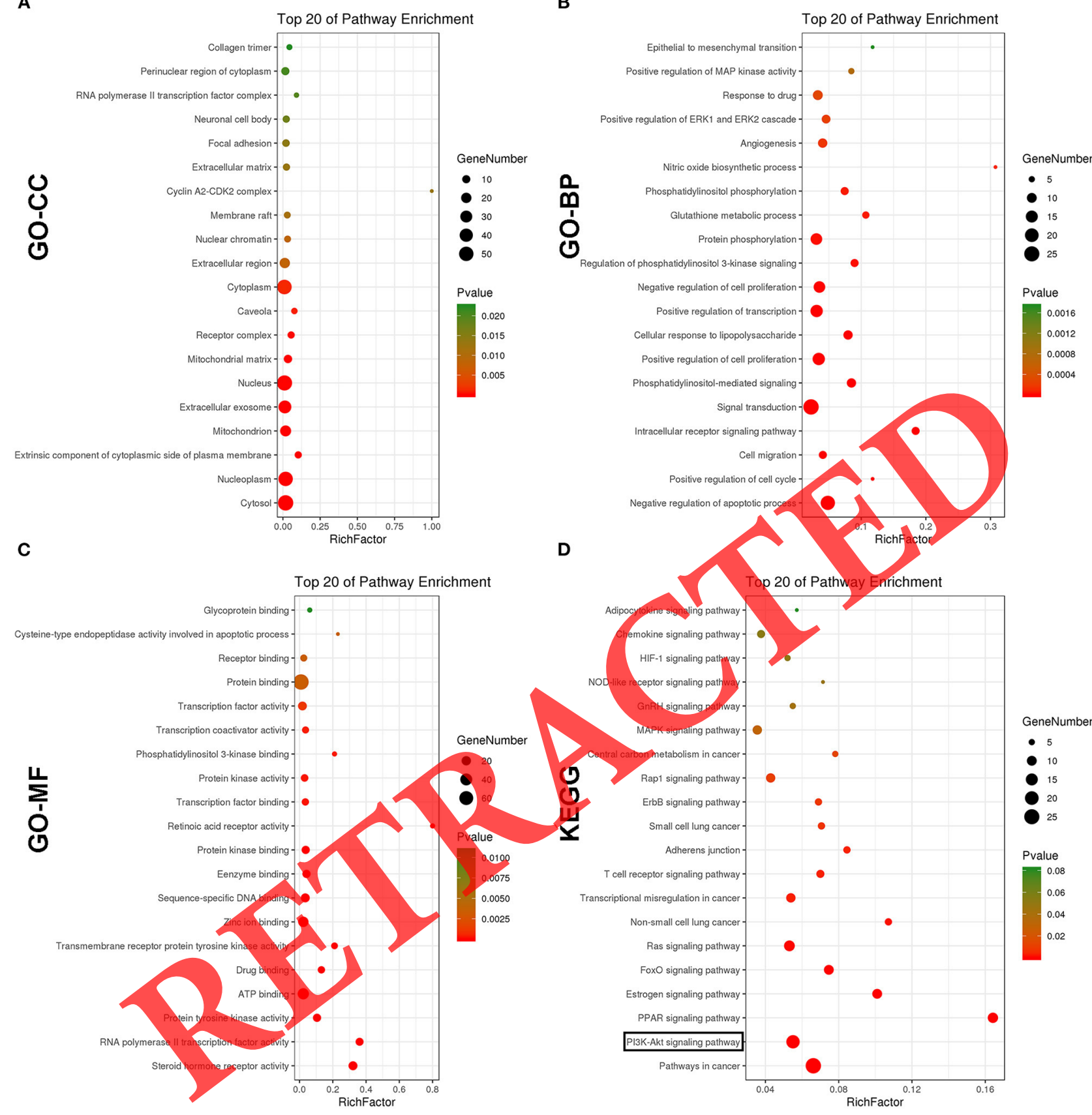

FIGURE 8 | GO and KEGG analyses. The top 20 signaling pathways of PTL in GO-Cellular Component analysis (A). The top 20 signaling pathways of PTL in GO-Biological Process analysis (A,B). The top 20 signaling pathways of PTL in GO-Molecular Function analysis (C). The top 20 signaling pathways of PTL in KEGG pathways analysis (D).

NSCLC therapy. Drugs targeting the apoptosis pathway (such as PTL) may also serve as an effective strategy for NSCLC therapy, and might play vital roles in minimizing adverse reactions, maximizing clinical efficacy, and helping to increase the quality of life for patients.

According to the results of our research, PTL combined with DDP could synergistically suppress NSCLC cells through the downregulation of the PI3K/Akt signaling pathway. In combination therapy, PTL was able to increase the sensitivity of NSCLC cells to DDP, allowing for its reduced dose, thereby potentially decreasing its side effects. This discovery provides the basis for PTL as a new option for combination therapy in the treatment of NSCLC.

In summary, our study showed that PTL could strengthen the pro-apoptotic effect of DDP on NSCLC cells through arresting cells at $\mathrm{S}$ and $\mathrm{G} 2 / \mathrm{M}$ phases, thus functioning as 


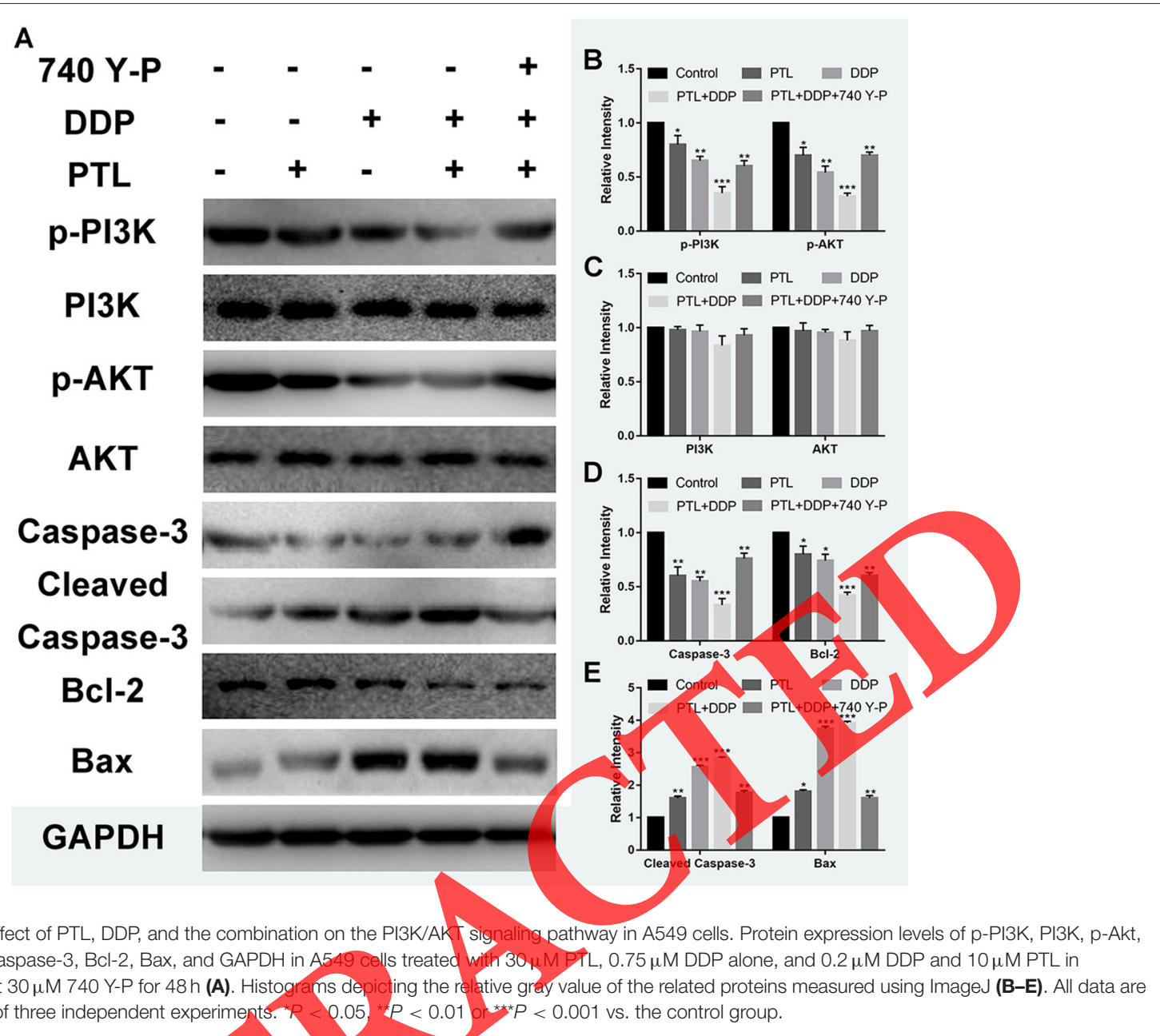

FIGURE 9 | Suppressive effect of PTL, DDP, and the combination on the PI3K/AKT Akt, Caspase-3, cleaved Caspase-3, Bcl-2, Bax, and GAPDH in A549 cells treated combination with or without $30 \mu \mathrm{M} 740 \mathrm{Y}-\mathrm{P}$ for $48 \mathrm{~h}$ (A). Histograms depicting the relative gray value of the related proteins measured using ImageJ (B-E). All data are shown as the mean $\pm S D$ of three independent experiments. ${ }^{\star} P<0.05$, $* P<0.01$ or $* \star * P<0.001$ vs. the control group.

an inducer of apoptosis. In the xenograft models, PJL and DDP combination demonstrated distinct anti-cancer activity and reduced tumor volumes and weights. Therefore, PTL has potential as a synergistic drug in combination with DDP to prevent NSCLC.

\section{DATA AVAILABILITY STATEMENT}

The raw data supporting the conclusions of this article will be made available by the authors, without undue reservation.

\section{ETHICS STATEMENT}

The animal study was reviewed and approved by Institutional Animal Care and Use Committee of Sun Yat-sen University.

\section{REFERENCES}

Araujo, T. G., Vecchi, L., Lima, P., Ferreira, E. A., Campos, I. M., Brandao, D. C., et al. (2019). Parthenolide and its analogues: a new potential strategy for the treatment of triple-negative breast tumors. Curr. Med. Chem. 39, 6628-6642. doi: 10.2174/0929867326666190816230121

\section{AUTHOR CONTRIBUTIONS}

W-HC, J-FZ, Z-RH, and S-QN designed the research. L-MW, $\mathrm{X}-\mathrm{ZL}, \mathrm{BK}, \mathrm{LS}$, and YZ performed the experiments. L-MW, X-ZL, $\mathrm{BK}$, LS, and YZ performed the data analysis. W-HC, J-FZ, $\mathrm{Z}-\mathrm{RH}$, and S-QN contributed to the guidance of the experiments. L-MW, X-ZL, and YZ wrote the manuscript. W-HC and J-FZ edited and revised the manuscript. All authors authorized the final version of the manuscript.

\section{FUNDING}

This research was funded by the National Natural Science Foundation of China (81774376, 81774175, 81874381, and 82074159) and Natural Science Foundation of Guangdong Province (2018A0303130121).

Asati, V., Mahapatra, D. K., and Bharti, S. K. (2016). PI3K/Akt/mTOR and Ras/Raf/MEK/ERK signaling pathways inhibitors as anticancer agents: structural and pharmacological perspectives. Eur. J. Med. Chem. 109, 314-341. doi: 10.1016/j.ejmech.2016.01.012

Aziz, S. A., Davies, M., Pick, E., Zito, C., Jilaveanu, L., Camp, R. L., et al. (2009). Phosphatidylinositol-3-kinase as a therapeutic target in 
melanoma. Clin. Cancer Res. 15, 3029-3036. doi: 10.1158/1078-0432.CCR08-2768

Berdan, C. A., Ho, R., Lehtola, H. S., To, M., Hu, X., Huffman, T. R., et al. (2019). Parthenolide covalently targets and inhibits focal adhesion kinase in breast cancer cells. Cell Chem. Biol. 26, 1027-1035.e1022. doi: 10.1016/j.chembiol.2019.03.016

Che, S. T., Bie, L., Li, X., Qi, H., Yu, P., and Zuo, L. (2019). Parthenolide inhibits the proliferation and induces the apoptosis of human uveal melanoma cells. Int. J. Ophthalmol. 12, 1531-1538. doi: 10.18240/ijo.2019.10.03

Chen, L. M., Song, T. J., Xiao, J. H., Huang, Z. H., Li, Y., and Lin, T. Y. (2017). Tripchlorolide induces autophagy in lung cancer cells by inhibiting the $\mathrm{PI} 3 \mathrm{~K} / \mathrm{AKT} / \mathrm{mTOR}$ pathway and improves cisplatin sensitivity in A549/DDP cells. Oncotarget 8, 63911-63922. doi: 10.18632/oncotarget.19201

Chen, W., Zheng, R., Baade, P. D., Zhang, S., Zeng, H., Bray, F., et al. (2016). Cancer statistics in China, 2015. CA Cancer J. Clin. 66, 115-132. doi: $10.3322 /$ caac. 21338

Chen, Z., Fillmore, C. M., Hammerman, P. S., Kim, C. F., and Wong, K. K. (2014). Non-small-cell lung cancers: a heterogeneous set of diseases. Nat. Rev. Cancer 14, 535-546. doi: 10.1038/nrc3775

Darwish, N. H. E., Sudha, T., Godugu, K., Bharali, D. J., and Elbaz, O. (2019). Novel targeted nano-parthenolide molecule against NF-kB in acute myeloid leukemia. Molecules 24:2103. doi: 10.3390/molecules24112103

Dasari, S., and Tchounwou, P. B. (2014). Cisplatin in cancer therapy: molecular mechanisms of action. Eur. J. Pharmacol. 740, 364-378. doi: 10.1016/j.ejphar.2014.07.025

Dillon, R. L., White, D. E., and Muller, W. J. (2007). The phosphatidyl inositol 3kinase signaling network: implications for human breast cancer. Oncogene 26, 1338-1345. doi: 10.1038/sj.onc. 1210202

Donahue, T. R., Tran, L. M., Hill, R., Li, Y., Kovochich, A., Calvopina, J. H., et al. (2012). Integrative survival-based molecular profiling of human pancreatic cancer. Clin. Cancer Res. 18, 1352-1363. doi: 10.1158/1078-0432.CCR-11-1539

Engelman, J. A., Luo, J., and Cantley, L. C. (2006). The evolution of phosphatidylinositol 3-kinases as regulators of growth and metabolism. Nat. Rev. Genet. 7, 606-619. doi: 10.1038/nrg1879

Farzadfar, S., Zarinkamar, F., Behmanesh, M., and Hojati, M. (2016). Magnesium and manganese interactively modulate parthenolide accumulation and the antioxidant defense system in the leaves of Tanacetum parthenium. I. Plant Physiol. 202, 10-20. doi: 10.1016/j.jplph.2016.06.017

Ghantous, A., Sinjab, A., Herceg, Z., and Darwiche, N, (2013). Parthenolide: from plant shoots to cancer roots. Drug Discoy. Today 18, 894-905. doi: 10.1016/j.drudis.2013.05.005

Gong, T., Cui, L., Wang, H., Wang, H., and Han, N. (2018). Knockdown of KLF5 suppresses hypoxia-induced resistance to cisplatin in NSCLC cells by regulating HIF-1alpha-dependent glycolysis through inactivation of the PI3K/Akt/mTOR pathway. J. Transl. Med. 16:164.doi: 10.1186/s12967-018-1543-2

Gridelli, C., Rossi, A., Carbone, D. P., Guarize, J., Karachaliou, N., Mok, T., et al. (2015). Non-small-cell lung cancen Nat. Rev. Dis. Primers 1:15009. doi: $10.1038 /$ nrdp. 2

Hamilton, G., and Rath, B. (2014). A short update on cancer chemoresistance. Wien Med. Wochenschr 164, 456-460. dor: 10.1007/s10354-014-0311-Z

Hennessy, B. T., Smith, D. L., Ram, P. T., Lu, Y., and Mills, G. B. (2005). Exploiting the PI3K/AKT pathway for cancer drug discovery. Nat. Rev. Drug Discov. 4, 988-1004. doi: 10.1038/nrd1902

Jeyamohan, S., Moorthy, R. K., Kannan, M. K., and Arockiam, A. J. (2016). Parthenolide induces apoptosis and autophagy through the suppression of PI3K/Akt signaling pathway in cervical cancer. Biotechnol. Lett. 38, 1251-1260. doi: 10.1007/s10529-016-2102-7

Katso, R., Okkenhaug, K., Ahmadi, K., White, S., Timms, J., and Waterfield, M. D. (2001). Cellular function of phosphoinositide 3-kinases: implications for development, homeostasis, and cancer. Annu. Rev. Cell Dev. Biol. 17, 615-675. doi: 10.1146/annurev.cellbio.17.1.615

Kelland, L. (2007). The resurgence of platinum-based cancer chemotherapy. Nat. Rev. Cancer 7, 573-584. doi: 10.1038/nrc2167

Kim, S. L., Park, Y. R., Lee, S. T., and Kim, S. W. (2017). Parthenolide suppresses hypoxia-inducible factor-1alpha signaling and hypoxia induced epithelial-mesenchymal transition in colorectal cancer. Int. J. Oncol. 51, 1809-1820. doi: 10.3892/ijo.2017.4166

Liu, J., Xing, Y., and Rong, L. (2018). miR-181 regulates cisplatin-resistant non-small cell lung cancer via downregulation of autophagy through the PTEN/PI3K/AKT pathway. Oncol. Rep. 39, 1631-1639. doi: 10.3892/or.2018.6268

Martini, M., De Santis, M. C., Braccini, L., Gulluni, F., and Hirsch, E. (2014). PI3K/AKT signaling pathway and cancer: an updated review. Ann. Med. 46, 372-383. doi: 10.3109/07853890.2014.912836

Ren, Y., Li, Y., Lv, J., Guo, X., Zhang, J., Zhou, D., et al. (2019). Parthenolide regulates oxidative stress-induced mitophagy and suppresses apoptosis through p53 signaling pathway in C2C12 myoblasts. J. Cell. Biochem. 120, 15695-15708. doi: $10.1002 /$ jcb. 28839

Rossi, A., and Di Maio, M. (2016). Platinum-based chemotherapy in advanced non-small-cell lung cancer: optimal number of treatment cycles. Expert Rev. Anticancer Ther. 16, 653-660. doi: 10.1586/14737140.2016.1170596

Shi, H., Pu, J., Zhou, X. L., Ning, Y. Y., and Bai, C. (2017). Silencing long non-coding RNA ROR improves sensitivity of non-small-cell lung cancer to cisplatin resistance by inhibiting PI3K/Akt/mTOR signaling pathway. Tumour Biol. 39:1010428317697568. doi: 10.1177/1010428317697568

Siegel, R. L., Miller, K. D., and Jemal, A. (2018). Cancer statistics, 2018. CA Cancer J. Clin. 68, 7-30. doi: 10.3322/caac. 21442

Stemke-Hale, K., Gonzalez-Angulo, A. M., Lluch, A., Neve, R. M., Kuo, W. L., Davies, M., et al. (2008). An integrative genomic and proteomic analysis of PIK3CA, PTEN, and AKT mutations in breast cancer. Cancer Res. 68, 6084-6091. doi: 10.1158/0008-5472.CAN-07-6854

Talib, W. H., and Al Kury, L. T. (2018) Parthenolide inhibits tumor-promoting effects of nicotine in lung cancer by inducing P53 - dependent apoptosis and inhibiting VEGF expression. Biomed. Pharmacother. 107, 1488-1495. doi: 10.1016/j.biopha.2018.08.1

Tang, T. K., Chiu, S. C., Lin, C. W. Su, M. J., and Liao, M. H. (2015). Induction of survivin inhibition, G(2)/M cell cycle arrest and autophagic on cell death in human malignant glioblastoma cells. Chin. J. Physiol. 58, 95-103. doi: 10.4077/CJP.2015.BAC267

Thomford, N. E., Senthebane, D. A, Rowe, A., Munro, D., Seele, P., and Maroyi, A. (2018). Natural products for drug discovery in the 21st century: innovations for novel drug discovery. Int. J. Mol. Sci. 19:1578. doi: 10.3390/ijms 19061578

Wang, D., Wang, H., Fu, S., Cheng, X., Yang, F., Zhang, Q., et al. (2016). Parthenolde ameliorates Concanavalin A-induced acute hepatitis in mice and modulates the macrophages to an anti-inflammatory state. Int. Immunopharmacol. 38, 132-138. doi: 10.1016/j.intimp.2016.05.024

Wang, X., Shen, Y., Wang, S., Li, S., Zhang, W., Liu, X., et al. (2017). PharmMapper 2017 update: a web server for potential drug target identification with a comprehensive target pharmacophore database. Nucleic Acids Res. 45(W1), W356-W360. doi: 10.1093/nar/gkx374

Xia, A., Li, H., Li, R., Lu, L., and Wu, X. (2018). Co-treatment with BEZ235 enhances chemosensitivity of A549/DDP cells to cisplatin via inhibition of PI3K/Akt/mTOR signaling and downregulation of ERCC1 expression. Oncol. Rep. 40, 2353-2362. doi: 10.3892/or.2018.6583

Yang, S., Si, L., Jia, Y., Jian, W., Yu, Q., Wang, M., et al. (2019). Kaempferol exerts anti-proliferative effects on human ovarian cancer cells by inducing apoptosis, G0/G1 cell cycle arrest and modulation of MEK/ERK and STAT3 pathways. J. BUON. 24, 975-981.

Zhang, D., Qiu, L., Jin, X., Guo, Z., and Guo, C. (2009). Nuclear factorkappaB inhibition by parthenolide potentiates the efficacy of Taxol in nonsmall cell lung cancer in vitro and in vivo. Mol. Cancer Res. 7, 1139-1149. doi: 10.1158/1541-7786.MCR-08-0410

Zhao, M., Xu, P., Liu, Z., Zhen, Y., Chen, Y., Liu, Y., et al. (2018). Dual roles of miR374a by modulated c-Jun respectively targets CCND1-inducing PI3K/AKT signal and PTEN-suppressing Wnt/beta-catenin signaling in non-small-cell lung cancer. Cell Death Dis. 9:78. doi: 10.1038/s41419-017-0103-7

Conflict of Interest: The authors declare that the research was conducted in the absence of any commercial or financial relationships that could be construed as a potential conflict of interest.

Copyright (c) $2021 \mathrm{Wu}$, Liao, Zhang, He, Nie, Ke, Shi, Zhao and Chen. This is an open-access article distributed under the terms of the Creative Commons Attribution License (CC BY). The use, distribution or reproduction in other forums is permitted, provided the original author(s) and the copyright owner(s) are credited and that the original publication in this journal is cited, in accordance with accepted academic practice. No use, distribution or reproduction is permitted which does not comply with these terms. 